\title{
Comparison of Haemophilus parasuis reference strains and field isolates by using random amplified polymorphic DNA and protein profiles
}

\author{
Emilie S Zehr ${ }^{\text {** }}$, Dennis V Lavrov² and Louisa B Tabatabai ${ }^{1}$
}

\begin{abstract}
Background: Haemophilus parasuis is the causative agent of Glässer's disease and is a pathogen of swine in high-health status herds. Reports on serotyping of field strains from outbreaks describe that approximately $30 \%$ of them are nontypeable and therefore cannot be traced. Molecular typing methods have been used as alternatives to serotyping. This study was done to compare random amplified polymorphic DNA (RAPD) profiles and whole cell protein (WCP) lysate profiles as methods for distinguishing H. parasuis reference strains and field isolates.

Results: The DNA and WCP lysate profiles of 15 reference strains and 31 field isolates of H. parasuis were analyzed using the Dice and neighbor joining algorithms. The results revealed unique and reproducible DNA and protein profiles among the reference strains and field isolates studied. Simpson's index of diversity showed significant discrimination between isolates when three 10mer primers were combined for the RAPD method and also when both the RAPD and WCP lysate typing methods were combined.

Conclusions: The RAPD profiles seen among the reference strains and field isolates did not appear to change over time which may reflect a lack of DNA mutations in the genes of the samples. The recent field isolates had different WCP lysate profiles than the reference strains, possibly because the number of passages of the type strains may affect their protein expression.
\end{abstract}

Keywords: Haemophilus parasuis, RAPD, SDS-PAGE

\section{Background}

Haemophilus parasuis causes Glässer's disease in pigs, with symptoms of fibrinous polyserositis, pericarditis, polyarthritis, and meningitis [1]. H. parasuis also causes septicemia and pneumonia without polyserositis and can be isolated from nasal passages of healthy swine. Introduction of conventionally raised pigs into segregated early weaning herds may result in infection and high economic losses because the latter lack immunity to $H$. parasuis $[2,3]$. $H$. parasuis also remains a problem in many high health status herds. Economic losses in 2006 in the United States were estimated at \$145 million dollars (Rodney B. Baker, Veterinary Diagnostic and

\footnotetext{
*Correspondence: emilie.zehr@ars.usda.gov

'Ruminant Diseases and Immunology, National Animal Disease Center, Agricultural Research Service, U. S. Department of Agriculture, Ames IA 50010, USA

Full list of author information is available at the end of the article
}

Production Animal Medicine, Iowa State University, personal communication); [4].

Haemophilus parasuis strains are classified into 15 serovars based on immunodiffusion of heat-stable polysaccharide antigens $[5,6]$. However, reagents for serotyping field isolates are not readily available, and a large number of isolates cannot be identified by serotyping and are designated as nontypeable (NT) [7]. Other serotyping methods, such as the indirect hemagglutination test [7-9] have been employed to identify NT isolates. Nonetheless, there are still NT isolates that do not have serovar-specific reagents and cannot be characterized. The virulence of each serovar was determined in specific pathogen free pigs [5].

Molecular typing techniques are increasingly used to identify field isolates including NT isolates. These methods include polymerase chain reaction-restriction fragment length polymorphism (PCR-RFLP) [10,11], enterobacterial repetitive intergenic concensus-polymerase chain reaction 
(ERIC-PCR) [12,13], restriction endonuclease analysis [14,15], multilocus enzyme electrophoresis (MEE) [16], and multilocus sequence typing (MSLT) analysis [17]. The molecular typing methods have shown that considerable genetic diversity exists among strains of isolates of a particular serotype and that the genotyping techniques were more discriminating compared to conventional serotyping, especially for use in epidemiological studies. Each of these molecular typing techniques offers advantages and disadvantages.

For example, restriction endonuclease experiments $[14,15]$ found distinct patterns of isolates from animals with systemic disease compared to respiratory isolates from healthy animals but restriction enzymes are expensive. The PCR-RFLP method uses restriction enzymes and sometimes does not generate multiple bands [11]. Multilocus sequence typing (MSLT) is a technique that studies housekeeping genes [17]. However, the latter procedure requires isolation of genomic DNA, performing PCR, and sequencing of PCR products. Both ERICPCR [12,13,18-20] and MSLT analysis [17] could detect strain variation but not all strains were classified as virulent or avirulent.

Although ERIC-PCR has recently been extensively used to study the epidemiology of $H$. parasuis isolates [19-21], the random amplified polymorphic DNA (RAPD) technique has not been utilized for this purpose. However, RAPD has been used to distinguish other gamma-proteobacteria, including Salmonella spp. [22], E. coli O157 [23], and Klebsiella pneumonia [24]. Both ERIC-PCR and random amplified polymorphic DNA (RAPD) are global techniques since known primers can be easily synthesized, reagents are affordable and readily obtained, and the techniques have high levels of reproducibility.

In the PCR-based RAPD method, DNA does not have to be double-stranded, highly purified, or of high molecular weight [25]. Both ERIC-PCR and RAPD can utilize DNA from crude lysates [13,26,27] which shortens the time needed for completing the assays. However, most laboratories prefer to purify genomic DNA before it is used in genome-based techniques, especially if it is to also be used in assays other than the ERIC-PCR technique [16,18-21,28].

The ERIC-PCR technique uses higher annealing temperatures (approximately $50-58^{\circ} \mathrm{C}$ ) and longer primers (20 nucleotides) than the RAPD method. These primers are specific for areas of the genome that are highly conserved and include an inverted repeat. The RAPD assay uses low stringency conditions of approximately $30-36^{\circ} \mathrm{C}$ annealing temperatures and short (10 nucleotide) primers. One or more of these arbitrarily chosen RAPD primers can anneal at multiple locations throughout the genome and amplify many products of the template DNA.
In addition to genomic-based methods, protein-based methods offer a different and complementary approach. Whole cell protein (WCP; [29-32] profiles or outer membrane protein profiles [33] of $H$. parasuis, which use a sodium dodecyl sulfate polyacrylamide gel electrophoresis (SDS-PAGE) technique have been described. These studies suggested that isolates from systemic sites had unique protein profiles. Isolates from respiratory sites had different protein profiles than the systemic isolates had. The $36-38.5 \mathrm{kDa}$ proteins were described as virulence markers based on the isolation site of the strain [32].

This work analyzed the DNA and protein profiles of $46 H$. parasuis reference and field isolates. Random amplified polymorphic DNA is a molecular typing technique that is often used to differentiate closely related strains. It is especially sensitive to strain variation when three optimized primers are employed [34-36]. Random amplified polymorphic DNA may detect single base changes in genomic DNA and genetic maps consisting of RAPD markers can be generated more efficiently than by using RFLP targeted PCR-based methods [28]. Intra-specific variation in the RAPD patterns can be observed for each primer and the sequence complexity of small plasmids is unlikely to contribute to the patterns [26]. However, bacteriophage and larger plasmids with transposons could possibly mediate horizontal gene transfer between strains and increase RAPD heterogeneity [18]. By using the relatively simple and economical RAPD technique, known primer sequences can be utilized by different laboratories, making it a standardized technique and amenable to epidemiological studies. However, interpretation of gel electrophoresis results could introduce some variability between laboratories. The objectives of this study were to compare the relatedness of the reference strains and field isolates based on the RAPD and WCP lysate profiles and to determine if clustering that occurred was related to the site of isolation or to the pathogenicity of the strain.

\section{Results}

\section{Comparison of RAPD profiles and pattern analysis}

Of the three primers used for genotyping, primer 2 had an intermediate number of bands; primer 7 had the most polymorphic DNA bands; and primer 12 had the least number of polymorphic DNA bands (Figure 1). Identical patterns were obtained for each isolate for each primer when the assays were performed in triplicate. Band sizes of DNA ranged between 220-3054 base pairs (bp). There were bands that were more densely stained than others, but all bands were treated identically. Four outgroup strains that were in the same family as $H$. parasuis but from different genera were included in the analysis. Fingerprints of DNA were unique for each 

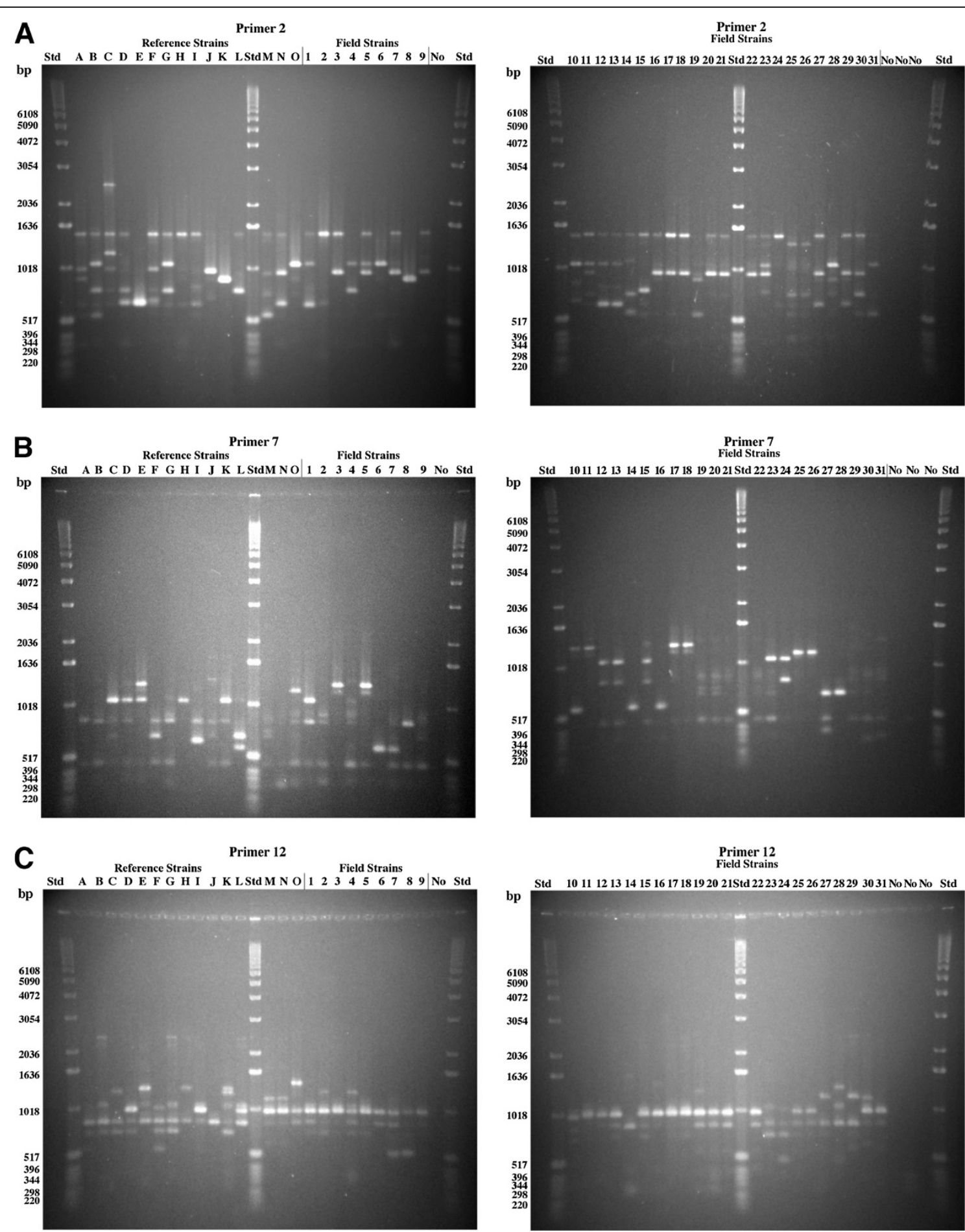

Primer 7
Field Strains

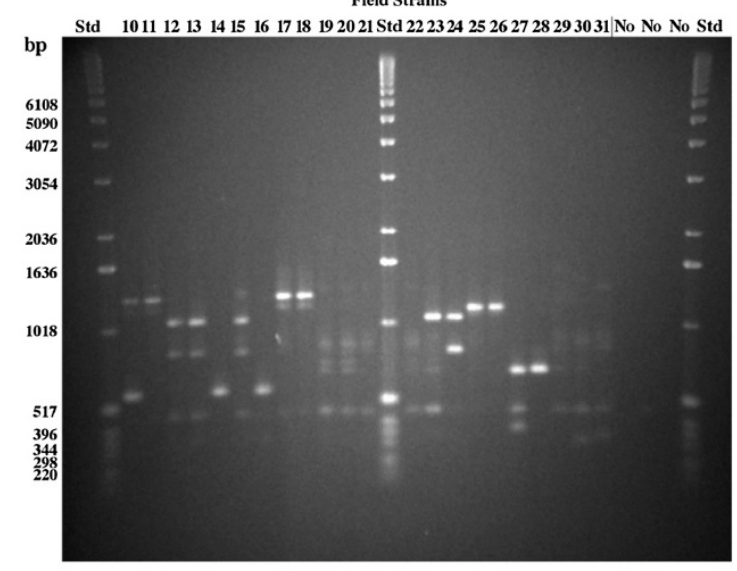

Primer 12
Field Strains

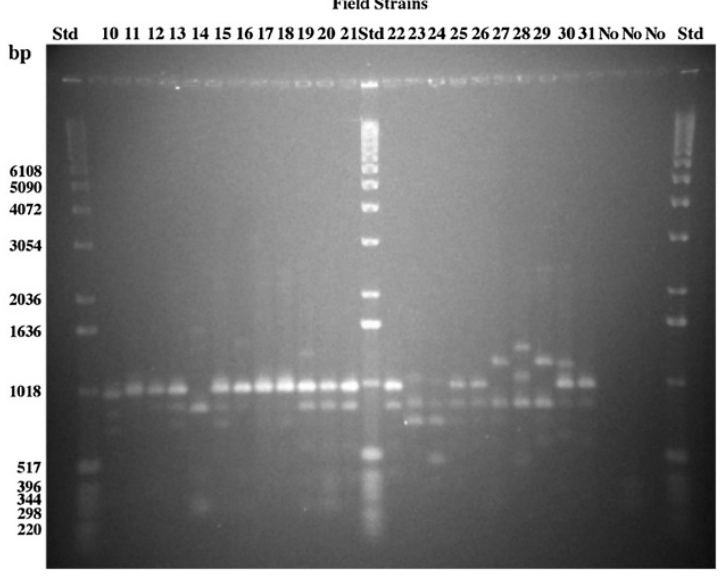

Figure 1 RAPD analysis of $H$. parasuis strains using primer 2 (panel A), primer 7 (panel B), and primer 12 (panel C). Reference strains A-O are described in Table 1. Reference strains were obtained between 1978 and 1990. Field strains 1-31 are described in Table 2. Field strains 1-24, 25-29, 30-31 were obtained in 2004, 1999, and 1984, respectively. Each lane was loaded with $10 \mu \mathrm{l}$ of PCR amplification product containing approximately 30 ng of DNA. A DNA control (no cells) was included in lanes marked "No". The Standard (Std) was a 1 kb DNA ladder. 
Table 1 Description of $H$. parasuis reference strains ${ }^{a}$

\begin{tabular}{|c|c|c|c|c|c|c|}
\hline$\#$ & Serovar & Strain & Country & Isolation Site & Diagnosis & Virulence $^{\mathbf{b}}$ \\
\hline $\bar{A}$ & 1 & No. 4 & Japan & Nose & Healthy & $\mathrm{H}$ \\
\hline B & 2 & SW140 & Japan & Nose & Healthy & $\mathrm{L}+$ \\
\hline$C$ & 3 & SW114 & Japan & Nose & Healthy & A \\
\hline $\mathrm{D}$ & 4 & SW124 & Japan & Nose & Healthy & $\mathrm{L}+$ \\
\hline$E$ & 5 & Nagasaki & Japan & Meninges & $\begin{array}{l}\text { Meningitis, } \\
\text { septicemia }\end{array}$ & $\mathrm{H}$ \\
\hline $\mathrm{F}$ & 6 & 131 & Switzerland & Nose & Healthy & A \\
\hline G & 7 & 174 & Switzerland & Nose & Healthy & A \\
\hline $\mathrm{H}$ & 8 & C5 & Sweden & Unknown & Unknown & L- \\
\hline । & 9 & D74 & Sweden & Unknown & Unknown & A \\
\hline J & 10 & $\mathrm{H} 367^{\mathrm{c}}$ & Germany & Unknown & Unknown & $\mathrm{H}$ \\
\hline K & 11 & $\mathrm{H} 465$ & Germany & Trachea & Pneumonia & A \\
\hline L & 12 & $\mathrm{H} 425$ & Germany & Lung & Polyserositis & $\mathrm{H}$ \\
\hline M & 13 & 84-17975 & United States & Lung & Unknown & $\mathrm{H}$ \\
\hline$N$ & 14 & $84-22113$ & United States & Joint & Septicemia & $\mathrm{H}$ \\
\hline $\mathrm{O}$ & 15 & 84-15995 & United States & Lung & Pneumonia & L+ \\
\hline
\end{tabular}

a originally published by Kielstein and Rapp-Gabrielson (1992) and adapted by Zehr and Tabatabai (2011).

${ }^{b} \mathrm{H}$, Highly virulent, death of pig within $96 \mathrm{~h}$ post-inoculation; L+, Polyserositis and arthritis at necropsy; L-, Mild clinical symptoms; A, Avirulent, no clinical symptoms at necropsy as described by Kielstein and Rapp-Gabrielson (1992).

${ }^{\mathrm{c}} \mathrm{H} 367$ (serovar 10) is a field strain with the same characteristics as the original H555. Reference strain H555 was lost during culture passage prior to our acquisition of the reference strains above.

outgroup isolate and different from the fingerprint of $H$. parasuis for each primer (Figure 2A).

A composite dendrogram prepared from the RAPD data obtained by using three primers is shown in Figure 3. At $48.5 \%$ similarity, this dendrogram showed three clades (A, B, and C) and two unique reference serovars, one virulent isolate (L) from Germany which caused polyserositis and one avirulent nasal isolate $(\mathrm{F})$ from Switzerland from a healthy animal. All except one of the isolates in Clade A were systemic. Clade B contained three avirulent reference strains from Sweden (I), Japan $(\mathrm{C})$, and Switzerland $(\mathrm{G})$. The remaining isolates in Clade B were isolated from "healthy" animals but were virulent ( $B$ and $D)$ reference strains or systemic (1$2,12-13,15,23-24)$ field isolates. Clade $C$ isolates were systemic $H$. parasuis with the exception of one avirulent reference strain isolated from the trachea of a pig diagnosed with pneumonia from Germany (Figure 1, strain $\mathrm{K})$ as well as all outgroup strains, $M$. haemolytica, $P$. trehalosi, A. pleuropneumoniae, and P. multocida. Duplicate cultures of $H$. parasuis IA84-29755 (systemic field isolate 31 ) and two outgroup strains ( $M$. haemolytica and $P$. trehalosi), which are closely related phylogenetically, were grouped within one branch of Clade C. Duplicate cultures of $H$. parasuis field isolate 31 (IA8429755) were included as controls and gave identical fingerprints when analyzed with primers 2, 7 and 12 .
Both of the recent field isolates in Clade A (7 and 9) could be serotyped and $79 \%$ of the recent field isolates in Clade C $(6,14,10-11,16-22)$ were typeable, whereas $72 \%$ of the recent field isolates $(1-2,12-13,15,24)$ in Clade B were classified as "Unk". Three isolates (20-22) from the same animal but with two different serotypes (4 and 5) clustered in the same clonal grouping (Figure 3).

\section{Comparison of SDS-PAGE protein profiles and pattern analysis}

Protein bands between 8 and 180 kilodalton $(\mathrm{kDa})$ were present in all of the reference strains and field isolates (Figure 4), as well as a few bands higher than $180 \mathrm{kDa}$ in four of the reference strains $\mathrm{C}, \mathrm{F}, \mathrm{H}$, and I, respectively. The latter reference strains corresponded to serovars 3 , 6 , 8 , and 9, respectively, which all designated as avirulent. Isolates gave identical patterns when the analysis was performed in triplicate. Each serovar showed unique band patterns, but there were also common protein bands among the reference serovars (lanes A-O) and field isolates (lanes 1-31). For example, reference strains $\mathrm{C}$ and $\mathrm{F}$ showed a common protein at $253 \mathrm{kDa}$; and reference strains $\mathrm{H}$ and $\mathrm{I}$ showed a common band at $217 \mathrm{kDa}$. All reference strains (lanes A-O) and field isolates 25-31 expressed prominent bands at $140 \mathrm{kDa}$ and $70 \mathrm{kDa}$ and all strains except reference strains $\mathrm{B}$ and $\mathrm{H}$ 
Table 2 Description of $\boldsymbol{H}$. parasuis field isolates ${ }^{a}$

\begin{tabular}{|c|c|c|c|c|c|}
\hline$\#$ & Serovar & Strain & U.S. state of origin & Isolation site & Diagnosis \\
\hline 1 & Unk $^{\mathrm{b}}$ & 10680 & Oklahoma & Lung, heart & Septicemia \\
\hline 2 & Unk & 12939 & North Carolina & Lung, heart & Pneumonia, polyserositis \\
\hline 3 & Unk & 15677 & Minnesota & Brain, heart & Pneumonia, polyserositis \\
\hline 4 & Unk & 17321 & Illinois & Brain, lungs & Septicemia, pneumonia, meningitis \\
\hline 5 & Unk & 24054 & lowa & Lung & Septicemia, polyserositis \\
\hline 6 & 4 & 24996 & lowa & Lung & Pleuritis, septicemia \\
\hline 7 & 12 & 25718 & lowa & Heart & Pericarditis \\
\hline 8 & Unk & 28803 & lowa & Cerebrospinal fluid, lung & Meningitis, septicemia \\
\hline 9 & 13 & 29612 & North Carolina ${ }^{c}$ & Brain, Lung, Joint & Pneumonia, meningitis \\
\hline 10 & 4 & 29613 & North Carolina ${ }^{c}$ & Lung & Septicemia \\
\hline 11 & 5 & 29614 & North Carolina ${ }^{c}$ & Multiple sites & Septicemia \\
\hline 12 & Unk & 29814 & lowa & Lung, joint & Septicemia \\
\hline 13 & Unk & 29864 & lowa & Brain, joint & Meningitis, septicemia \\
\hline 14 & 5 & 30059 & lowa & Lung & Septicemia \\
\hline 15 & Unk & 32585 & lowa & Lung & Pneumonia, polyserositis \\
\hline 16 & 12 & 33105 & Missouri & Lung & Meningitis, pneumonia, polyserositis, septicemia \\
\hline 17 & 12 & 33206 & lowa & Brain, lung, joint & Pneumonia, septicemia \\
\hline 18 & 12 & 33808 & Minnesota & Lung, joint & Polyserositis, septicemia \\
\hline 19 & 5 & $34086 a$ & lowa ${ }^{d}$ & Lung, joint & Septicemia \\
\hline 20 & 5 & $34086 b$ & lowa & Lung, joint & Septicemia \\
\hline 21 & 4 & $34086 c$ & $\operatorname{lowa}^{d}$ & Lung, joint & Serositis, septicemia \\
\hline 22 & 4 & $34086 d$ & lowa & Lung, joint & Pneumonia, pleuritis, septicemia \\
\hline 23 & 2 & 35036 & lowa & Lung & Pneumonia, polyserositis \\
\hline 24 & Unk & 1269 & lowa & Heart, lung & Septicemia \\
\hline 25 & Unk & $831541^{\mathrm{e}}$ & lowa & Probably lung & Unknown $^{f}$ \\
\hline 26 & Unk & $831542^{\mathrm{e}}$ & lowa & Probably lung & Unknown $^{f}$ \\
\hline 27 & Unk & $464-99^{\mathrm{e}}$ & North Carolina & Joint & Polyserositis \\
\hline 28 & Unk & $685-99^{e}$ & North Carolina & Pericardial sac & Polyserositis \\
\hline 29 & Unk & $1050-99^{e}$ & North Carolina & Lung & Polyserositis \\
\hline 30 & Unk $\mathrm{k}^{\mathrm{b}, \mathrm{g}}$ & $2170 B$ & lowa & Joint & Polyserositis \\
\hline 31 & 5 & $84-29755$ & lowa & Lung & Pneumonia, pleuritis \\
\hline
\end{tabular}

a originally published by Zehr and Tabatabai (2011).

bUnk, did not serotype to serovars $2,4,5,12,13$, or 14 .

'Isolated from same farm site.

disolated from same animal.

e"Old" field strains obtained in 1999.

fSick animal.

${ }^{9}$ Originally serotype 4 in 1984.

(serovars 2 and 8, respectively) showed prominent bands at approximately $40 \mathrm{kDa}$. Visual inspection of the protein profiles of the field strains 25-31 (Figure 4) showed that these were similar to but not identical to reference strains $\mathrm{K}$ and L. Field strains $1-24$ protein profiles were more heterogeneous than the reference strains or field isolates 25-31 protein profiles. Field isolates 3, 6, 13, 20, and 29 all had major protein bands at approximately $50 \mathrm{kDa}$, which were not apparent in the other protein profiles. Outgroup strains (Figure 2B) had unique WCP lysate patterns, which differed from the $H$. parasuis pattern, on an SDS-PAGE gel.

The neighbor joining dendrogram showing phylogenetic analysis of WCP lysates (Figure 5) used a band optimization of $1.12 \%$ and a band position tolerance of $1.1 \%$ and had one unique isolate (field strain 13 which was isolated from the brain and joint and had the $50 \mathrm{kDa}$ band). Three clades (A, B, and C) at $58.5 \%$ 

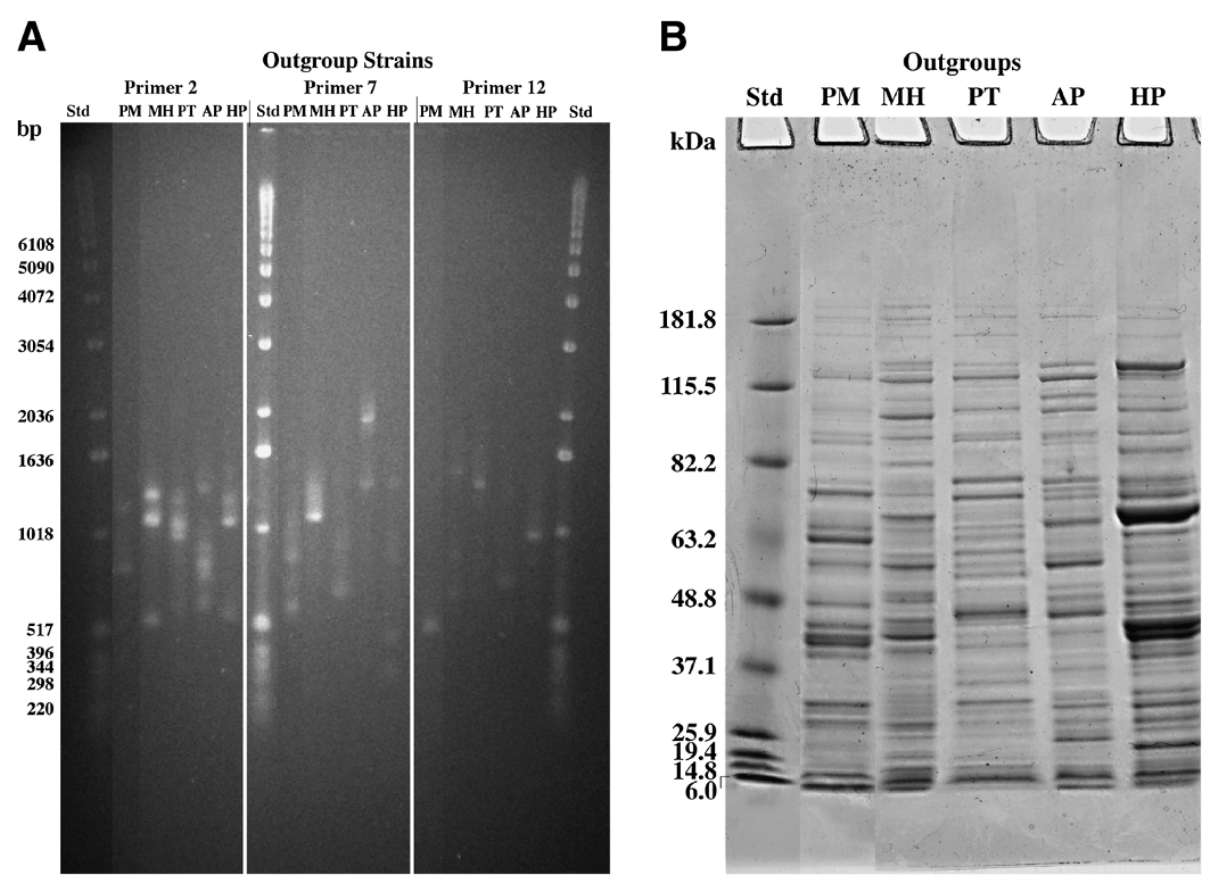

Figure 2 Characterization of outgroup strains by RAPD analysis and by WCP profiles. (A) RAPD analysis of four outgroup strains using primers 2, 7, and 12: Pasteurella multocida (PM), Mannheimia haemolytica (MH), Pasteurella trehalosi (PT) and Actinobacillus pleuropneumoniae (AP). The H. parasuis IA84-29755 (HP) fingerprint is shown for comparison to outgroup strains. Std was 1 kb DNA ladder; (B) SDS-PAGE analysis of WCP lysates of outgroup strains, samples were identical to those in panel A; Molecular weights (Std) are indicated in kilodaltons.

similarity were generated and three subclades of Clade A at $63 \%$ similarity were produced. Subclade A1 contained all systemic field isolates (Figure 5, Table 2). Subclade A2 contained eleven of the fifteen original reference strains of various pathogenicities and isolation sites (Table 1). Subclade A3 contained four of the fifteen original reference strains of varied diagnosis as well as the duplicate systemic field strains $H$. parasuis (field isolate 31 and IA84-29755) and all of the outgroup strains. Clade B contained field isolate 25 from 1999 and eight systemic field isolates $(1-2,4-5,6-7,10-11)$ from 2004 and Clade $\mathrm{C}$ contained 14 systemic field isolates (8-9, 12, 14-24) from 2004 (Figure 5, Table 2).

Isolates in Clades B and C clustered all of the systemic type and Subclade A2 strains were entirely of the reference type, including four (C, F, G, K) of the five avirulent strains. The majority (four out of five) of field isolates from 1999 (26-29) were clustered in Subclade A1 (Figure 5). Additionally, all three of the North Carolina isolates (27-29) grouped in Subclade A1. There appeared to be some discrimination as to state of origin between isolates in Clades $\mathrm{B}$ and $\mathrm{C}$ because there were three North Carolina (2,10-11), one Illinois (4), and one Oklahoma (1) isolates among the nine Clade B isolates whereas there were only one North Carolina (9), one Missouri (16), and one Minnesota (18) isolates among fifteen Clade $\mathrm{C}$ isolates. As with the RAPD neighbor joining analysis (Figure 3), recent field isolates seemed to group by serotype with $56 \%$ and $27 \%$ of the isolates in Clades B and C, respectively, not being serotyped to serovars $2,4,5,12,13$, or 14 .

\section{Discrimination of isolates using Simpson's index of diversity}

Simpson's index of diversity estimates the discriminatory ability of typing systems by calculating the discrimination index (D). D is the probability that two unrelated strains randomly selected from the test population are in two different typing groups. The only RAPD with a single primer that gave a significant index level of discrimination above 90\% was RAPD7 (Table 3). Groups and singletons were determined by using 55\% similarity for the composite RAPD (Figure 3) and $63 \%$ similarity for the WCP lysate (Figure 5). Combining the results of all 3 primers gave an index of 94.11\%. While the WCP lysate index was less than $90 \%$, combining it with the composite RAPD gave an index of diversity of $97.3 \%$.

\section{Discussion}

This study was undertaken to utilize the RAPD technique and SDS-PAGE protein profiles in order to compare 15 reference strains and 31 field isolates of $H$. parasuis to establish if a relationship existed between a 


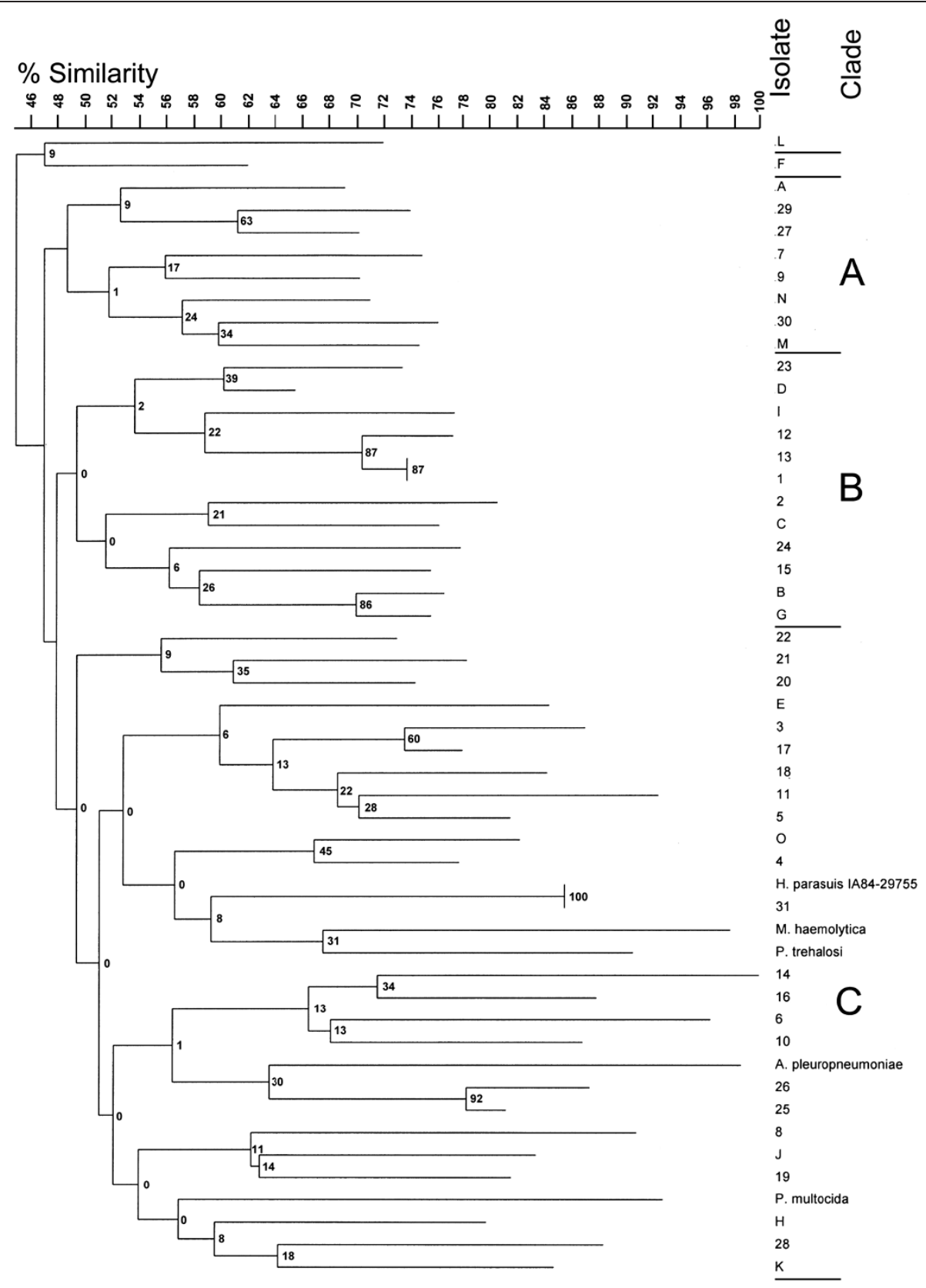

Figure 3 Dendrogram grouping based on the composite RAPD electrophoretic band patterns of representative H. parasuis strains and outgroup strains. Band patterns from all three single-primer experiments were combined to obtain a composite-primer RAPD dendrogram. Reference strains are designated A-O (Table 1), field isolates are designated 1-31 (Table 2), and outgroups are Pasteurella multocida (PM), Mannheimia haemolytica (MH), Pasteurella trehalosi (PT) and Actinobacillus pleuropneumoniae (AP). Three clade designations are shown. Reference strains were obtained between 1978 and 1990. Field strains 1-24, 25-29, 30-31 were obtained in 2004, 1999, and 1984, respectively. Numbers at the nodes indicate percentages of bootstrap values after 1000 replicates.

particular clustering profile or if there was a relationship to the site of isolation or to the pathogenicity of the strain. The clinical origin and pathogenesis of a strain is an indication of its virulence, but conclusions as to its virulence cannot be made in our study because pathogenesis studies were not conducted in specific pathogen free pigs [5]. However, the virulence potential of $H$. parasuis strains, based on their serotype classification, isolation sites and the presence or absence of major proteins with molecular weights between 36 and $38.5 \mathrm{kDa}$, has been investigated [30,33,37]. Some of the expressed proteins in our recent field isolates may be called virulence markers but no direct association of the $40 \mathrm{kDa}$ proteins could be made. Few laboratories have the 

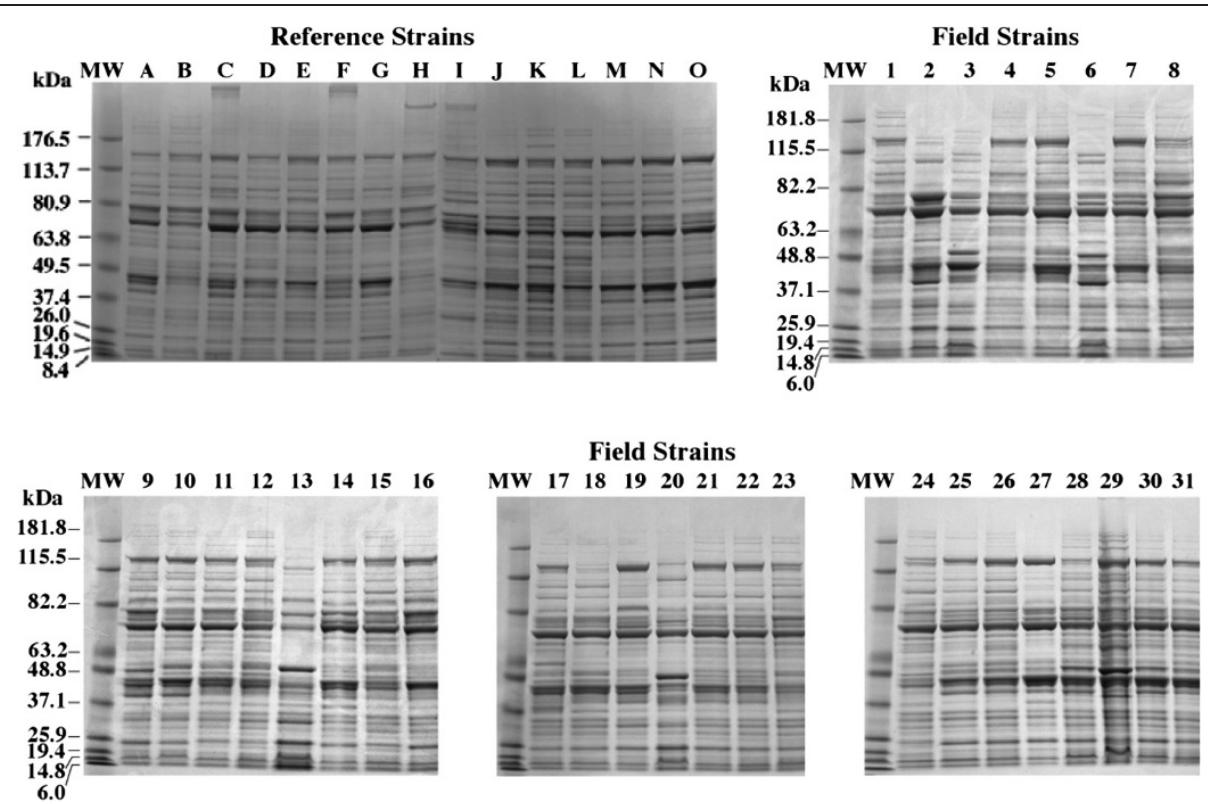

Field Strains

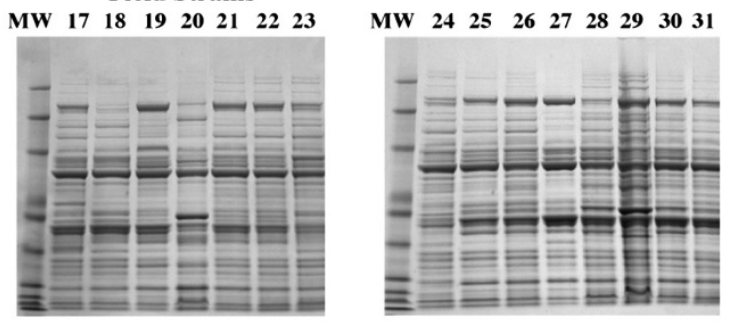

Figure 4 SDS-PAGE profiles of representative $H$. parasuis strains. Gradient SDS-PAGE gels of WCP lysates were stained with Coomassie Brilliant Blue R250. Reference strains A-O are described in Table 1. Reference strains were obtained between 1978 and 1990. Field strains 1-31 are described in Table 2. Field strains 1-24, 25-29, 30-31 were obtained in 2004, 1999, and 1984, respectively. Each lane was loaded with $10 \mu \mathrm{g}$ of protein. Molecular weights (MW) are indicated in kilodaltons.

ability to serotype $H$. parasuis isolates because of the lack of reagents. Therefore, a genome-based method and a phenotypic analysis of the reference strains and field isolates were emphasized in our study.

Neighbor joining analysis based on Dice coefficients of similarity was used to compare RAPD and protein (WCP lysate) profiles of the reference strains and field isolates. The samples were statistically discriminated better by using the composite RAPD technique than by using the WCP lysate technique but combining the results of both techniques gave a high discrimination index. Outgroups were included to compare the presence or absence of bands in these isolates to the bands in the more closely related $H$. parasuis isolates. The only monophyletic ingroup with the four "outgroups" was the SDS-PAGE dendrogram as determined by the neighbor joining analysis (Figure 5, Clade A3). The results suggest that the four outgroup species selected may have been too closely related to $H$. parasuis to act as a true outgroup. Dijkman et al. [20] were also unable to discriminate $A$. minor and $A$. porcinus strains from $H$. parasuis strains in an ERIC-PCR technique. Additionally, Olvera et al. [18] could not demonstrate that A. indolicus and $A$. minor strains were outgroups to $H$. parasuis strains when they used the variation of the partial $h s p 60$ sequence of $H$. parasuis as a classification tool.

Others have shown that the geographic distribution or age of the isolate may cause the "outgroup" to act as an ingroup [38] and that if the isolates in the study were too closely related, then the outgroups could be rerooted to locations within phylogenetic trees [39]. A fourth possibility for the lack of outgroup observance in the dendrograms could be that horizontal gene transfer has occurred between the outgroup species and $H$. parasuis [40], which would cause unexpected similarities and unusual phyletic patterns [18]. This theory is supported by the presence of bacteriophages in $H$. parasuis [41-43], $E$. coli [44], P. multocida [45], M. haemolytica [46], and $P$. trehalosi [47], plasmids in $H$. parasuis [48] and A. pleuropneumoniae [49], and a DNA uptake sequence in $H$. parasuis [50].

Although isolates from known systemic sites [51] (lung in an animal with polyserositis, joint, brain, heart, or septicemia) were able to be separated into groups by the RAPD technique described here, the composite diagram of the three individual primers ultimately showed a limited degree of relatedness based on pathogenicity among the reference strains and the 31 field strains. The strains showed high heterogeneity with the RAPD method which indicated possible horizontal transfer of genes or chromosomal recombination between unrelated and potentially transient strains.

Wang et al. [25] compared RAPD and MEE and found that RAPD data that combined five primers was more discriminatory than MEE tests that used 34 enzymes. The ERIC-PCR technique is a comparable method to RAPD. Zulkifli et al. [52] found RAPD to be more discriminatory than ERIC-PCR. Some $H$. parasuis isolates 


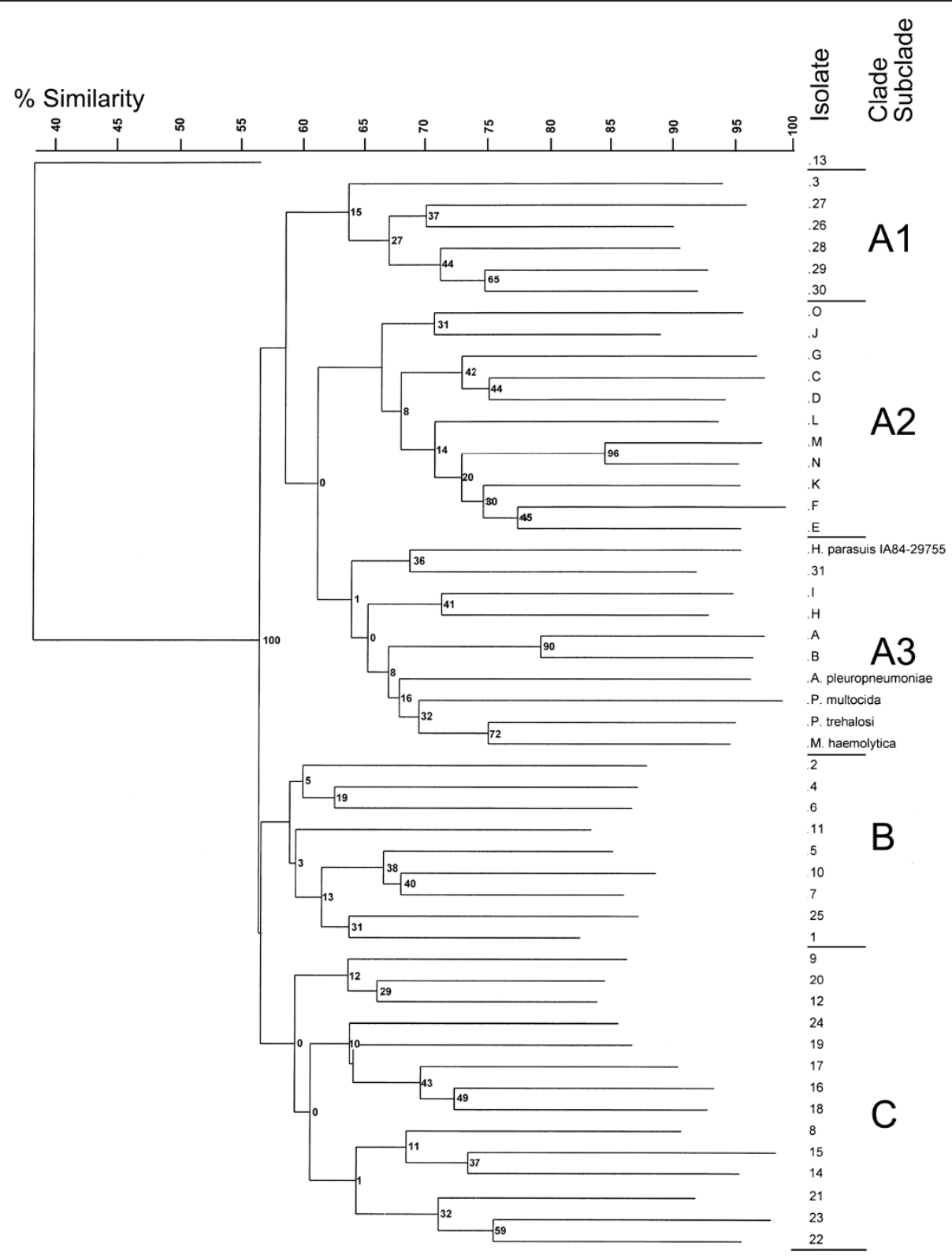

Figure 5 Dendrogram grouping based on the SDS-PAGE WCP lysate profiles. Reference strains are designated A-O (Table 1), field isolates are designated 1-31 (Table 2), and outgroups are Pasteurella multocida (PM), Mannheimia haemolytica (MH), Pasteurella trehalosi (PT) and Actinobacillus pleuropneumoniae (AP). Reference strains were obtained between 1978 and 1990. Field strains 1-24, 25-29, 30-31 were obtained in 2004, 1999, and 1984, respectively. Three clade and three subclade designations are shown. Numbers at the nodes indicate percentages of bootstrap values after 1000 replicates.

were not able to be assayed by using the ERIC-PCR [20] because they gave no or very poor results. Recent studies have found a high diversity of $H$. parasuis strains isolated in various geographic areas but have not been able to assign a clear correlation between virulence or serovar and ERIC-PCR clusters [19-21]. This conclusion agrees with other $H$. parasuis ERIC-PCR studies [12,18]. Macedo et al. [21] reported that the highest diversity was in the NT isolates which discriminated 23 genotypes. Our RAPD dendrogram also indicated high diversity of the $H$. parasuis strains, with only field isolates 1 and 13 being identical. Although there was no definite correlation between serovar and pathogenicity, most of the isolates that were serotypeable and from diseased animals clustered in Clade C.

Other genomic methods such as MEE and MLST $[16,17]$, also did not completely discriminate field isolates of $H$. parasuis. Blackall et al. [16] found 34 different electrophoretic types from 40 field isolates and 8 reference serovars, which clustered into 2 major subdivisions, 


\begin{tabular}{|c|c|c|c|c|}
\hline $\begin{array}{l}\text { Characterization } \\
\text { method }\end{array}$ & $\begin{array}{l}\text { No. of } \\
\text { groups }\end{array}$ & $\begin{array}{l}\text { Simpson's } \\
\text { index of } \\
\text { diversity }\end{array}$ & $\begin{array}{l}95 \% \\
\text { confidence } \\
\text { level }\end{array}$ & $\begin{array}{l}\text { No. of } \\
\text { samples } \\
\text { in largest } \\
\text { group }\end{array}$ \\
\hline RAPD2 $^{\mathrm{b}}$ & 17 & 85.70 & $78.44-92.96$ & 15 \\
\hline RAPDT $^{c}$ & 18 & 92.17 & $88.59-95.76$ & 8 \\
\hline RAPD $12^{d}$ & 19 & 89.66 & $84.43-94.90$ & 11 \\
\hline RAPDC $^{e}$ & 16 & 94.11 & $92.07-96.15$ & 6 \\
\hline$W C P^{f}$ & 9 & 88.60 & $84.77-92.43$ & 11 \\
\hline WCP/RAPDC ${ }^{\mathrm{g}}$ & 63 & 97.30 & $96.63-97.97$ & 15 \\
\hline
\end{tabular}

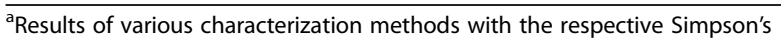
index of diversity value, $95 \%$ confidence interval, and the number of samples in the largest group produced by the method.

${ }^{b}$ RAPD bands using only primer 2 .

'RAPD bands using only primer 7 .

${ }^{\mathrm{d}} \mathrm{RAPD}$ bands using only primer 12 .

${ }^{e}$ Composite RAPD combining bands from all three primers.

'Whole cell protein lysate.

${ }^{9}$ Combination bands from whole cell protein lysate and composite RAPD.

which were not associated with virulence. Olvera et al. [17] concluded that subgroups of 120 field isolates and 11 reference serovars clustered into branches containing avirulent, nasal isolates and virulent, systemic isolates. However, 36 additional clinical isolates did not cluster within the virulent branch.

Two different studies $[53,54]$ combined serotyping and IHA methods and concluded that isolates of serovars 4, 5,13 , and NT isolates were the most prevalent in 2004 and 2005, with serovar 4 the most frequently isolated from the respiratory tract while NT isolates were usually systemic isolates. This study's field isolates were known to be systemic except for isolates 25 and 26, and included serovars $2,4,5,12$, and 13 , identified by available serotyping reagents. The serovars used in this study were the six most prevalent in the United States and Canada $[51,55]$. The range of NT $(15-31 \%)$ to the frequency of identification of serovars $2,4,5,12,13$, and 14 (76-41\%), respectively, by immunodiffusion [32] compares to the frequencies of our "Unk" (51.6\%) and six identified serovars (48.3\%). Some of our field isolates may have lost the expression of their polysaccharide capsule in vitro and may not be able to be serotyped presently $[12,51]$ as can be inferred from field isolate 30 , which was serotype 4 in 1999 but "Unk" in our study. Field isolate 30 may have lost an enzyme involved in the polysaccharide capsule synthesis. All of our field isolates of known serotype were associated with animals with systemic disease. The majority of field isolates of known serotype were in clade $\mathrm{C}$ of the RAPD experiment except for isolates 7, 9, and 23 and in clades B and C of the WCL experiment. Rapp-Gabrielson and Gabrielson [51] and Olvera et al. [17] noted that the distribution of $H$. parasuis serovars isolated from healthy animals may differ from that found in diseased animals and that more than one serovar could be isolated from the same animal or same isolation site. Our study also identified isolates with different serovars within the same farm site (field isolates 9-11) and in from the same isolation sites in the same animal (field isolates 19-22). "Unk" isolates with septicemia were the most prevalent, indicating that NT isolates harboring bacteriophages, plasmids, or repetitive elements may influence genotyping methods [40]. There may not have been a correlation between serotype and RAPD because only a small number of genes is involved in serotyping while the entire genome is analyzed with the RAPD technique [22].

Our SDS-PAGE results agree with those of Oliviera and Pijoan [30] who reported that isolates from systemic sites were usually virulent and clustered together as shown by using a computer-based analysis of protein profiles from serovars $1,2,4,5,7,12,13,14$ and nontypeable (NT) isolates. Their results are similar to protein profiles described in our study for field isolates and their isolation sites and pathogenesis as shown in the WCP lysate dendrogram of Figure 5 and Table 2. The field strains clustered in Subclade A1 and Clades B and $\mathrm{C}$ were primarily systemic. Ruiz et al. [33] found different OMP profiles between isolates from healthy pigs and those from diseased pigs. However, they concluded that respiratory isolates were more heterogeneous than systemic isolates.

Four studies have stated that a protein of approximately 36-38.5 kDa may be associated with Glässer's disease $[29,30,33,56]$. In this work, a protein band was observed at approximately $40 \mathrm{kDa}$ in all of the field isolates and thirteen of fifteen of the reference strains (Figure 4). The results shown for the WCP lysate dendrogram (Figure 5) imply that protein expression may be related to age or number of passages of the isolatein vitro, because reference strains clustered together, as did the "old" field strains (26-29) isolated in 1999 (Figure 5, Subclades A2 (C-G, J-O), A3 (A-B, H-I), and A1 (26-29), respectively). The phenotypic change of an isolate after serial passage was also reported by Rapp-Gabrielson and Gabrielson and Oliviera et al. [12,57]. Although we had only seven samples from North Carolina, three isolates (27-29) from 1999 grouped together in Subclade A1 of the SDS-PAGE neighbor joining dendrogram (Figure 5). Our WCP lysate patterns easily discriminated between A. pleuropneumoniae serotype 1 and $H$. parasuis as well as the other three outgroup strains (Figure 2B). Identical $H$. parasuis field isolates (H. parasuis IA84-29755 and 31) (Figure 5), bands did not match sufficiently to obtain identity in the protein profile computer analysis. This may have been because the bands were not fully "matched" in the Gel Compar II program. They were, however, in the same clonal branch of Subclade A3. 
Oliviera and Pijoan [30], Kielstein and RappGabrielson [5], Rosner et al. [58] and Blackall et al. [59] did not find any correlation between virulence and serotype of the isolate. However, the results reported in this study seem to indicate an association of virulence with isolates of Clade $\mathrm{C}$ in the WCP lysate analysis. There also seemed to be more serotypeable isolates among the recent field isolates of Clade $\mathrm{C}$. This work also found that the genome-based RAPD composite analysis method (Figure 3) showed more heterogeneity than the protein-based WCP lysate analysis, which grouped isolates according to length of passage in vitro and to possible geographic origin (Figure 5). The underlying genome did not change as much as the protein expression did over time [10].

The recent field isolates from this study were obtained from swine diagnosed mostly with septicemia caused by serovars $2,4,5,12$, and 13 . All of the isolates from diseased animals grouped into clades in the RAPD neighbor joining dendrogram containing systemic isolates (Figure 3, Clades A and C) or subclade or clades (Subclade A1 and Clades B and C) in the WCL neighbor joining dendrogram containing systemic isolates (Figure 5). Bootstrap values were low for both dendrograms. We did not raise bootstrap cut-off values because others have reported that gains and losses of genes may not be reflected when higher cut-off values are used in the analysis [60].

In order to estimate the discriminatory ability of the primers in the RAPD typing system and of the protein profiles, we used Simpson's index of diversity. The Simpson's index of diversity calculation assumes that samples are randomly selected from the population and that all groups are equally represented in the population. Samples in this study were from a few respiratory sites and mostly from diseased animals. Additionally, certain strains may be overrepresented because of their increased pathogenicity in diseased animals. However, if Simpson's assumptions were not met, a decrease in discrimination would be expected. This was not the case in our study because differences between strains and isolates were seen in both the composite RAPD or WCP lysate results as shown in Table 3.

\section{Conclusions}

The results of this study suggested that reference strains, "old" strains isolated in 1999, and recent field strains isolated in 2004 clustered by age of isolate when using WCL methods but not by using RAPD methods. Both the RAPD and the SDS-PAGE methods clustered strains from systemic sites. There was no strong correlation between site of isolation and genotype or between the RAPD and WCL techniques in this study. The RAPD technique showed the high heterogeneity of the $H$. parasuis isolates, whereas the protein profiles indicated that the number of passages in vitro of an isolate may affect its protein expression. The protein profiles of $H$. parasuis and A. pleuropneumoniae were unique and this WCP lysate technique may be useful as a tool to differentiate the two NAD-dependent swine respiratory organisms. The protein studies suggested that expressed genes of the organism may help to elucidate the virulence factors involved in the infection. Moreover, the relatively low cost, including supplies and equipment and relatively short amount of time required to perform the RAPD and WCP lysate methods are more advantageous when compared to other genomic or protein methods.

\section{Methods}

\section{Strains and growth conditions}

Fifteen $H$. parasuis type strains (reference strains A-O) were obtained from Richard Ross of the College of Veterinary Medicine, Iowa State University, Ames, Iowa and isolated between 1978 and 1990 [5,29]. Table 1 and Table 2 describe the $H$. parasuis strains used in this study. Field strains $1-24$, the most recently procured in 2004, were from Lorraine Hoffman of the Veterinary Diagnostic Laboratory, Iowa State University, Ames, Iowa. Field strains 25-29 obtained in 1999 were from Karen Post, Rollins Diagnostic Laboratory in North Carolina, while field strains 30 and 31 were obtained from Richard Ross in 1999 and were originally isolated in 1984. Duplicate cultures of $H$. parasuis IA84-29755 (field strain 31), a systemic 1984 field isolate, were included in the procedures as controls.

Because of commercial unavailability of typing sera, partial serotyping with antisera to serotypes $2,4,5,12$, 13, and 14 of all 31 field strains was performed by Gallant Custom Laboratories, Cambridge, Ontario. Strains that did not type by agar gel immunodiffusion to the previously mentioned six serotypes were designated as "Unk" which included NT and possible other serotypes of minor prevalence in the United States and Canada. Strains were grown in Frey's mycoplasma base broth (Sigma, St. Louis, MO) containing 20\% heatinactivated horse serum (Invitrogen, Carlsbad, CA) and $0.016 \% \beta$-nicotinamide adenine dinucleotide $(\beta$-NAD) (Sigma) at $37^{\circ} \mathrm{C}$ overnight. Strains were checked for purity on blood agar with a nurse streak of $S$. aureus across a lawn of the $H$. parasuis isolate and on Casman's agar (Difco, Detroit, MI) containing 5\% horse serum and $0.016 \% \beta$-NAD. Cultures were incubated at $37^{\circ} \mathrm{C}$ under humidified $5 \% \mathrm{CO}_{2}$.

\section{Outgroup analysis}

Strains were also studied in both RAPD and WCP lysate experiments in order to include related organisms to $H$. 
parasuis, of the Pasteurellaceae family, but ones that were not of the same species. The outgroup members serve as a reference group for determination of the evolutionary relationship among all the members of the comparison. An outgroup is hypothesized to branch from the ancestral group before the other groups branched from each other in the phylogenetic tree [61]. Selected outgroup organisms were Actinobacillus pleuropneumoniae (ATCC 27088), Pasteurella multocida (ATCC 15742), Mannheimia haemolytica (ATCC 43270, serotype A1), Pasteurella trehalosi (ATCC 29703, serotype T3), which were all members of the family Pasteurellaceae.

\section{RAPD analysis}

After screening several arbitrary 10mer primers from kit A (Operon Technologies, Alameda, CA), three primers with sequences of 5'-TGCCGAGCTG-3' (primer 2); 5'GAAACGGGTG-3' (primer 7); and 5'-TCGGCGATAG3' (primer 12) were each used individually. Primers were reconstituted in Tris-EDTA (pH 7.4) and titrated in initial assays in order to obtain the optimum amplification product. $H$. parasuis isolates, grown from $48-72 \mathrm{~h}$ on Casman's agar at $37^{\circ} \mathrm{C}$ under humidified $5 \% \mathrm{CO}_{2}$, were suspended in distilled water, then serially diluted 10-fold. The cell dilution that produced approximately $3 \mathrm{ng} / \mu \mathrm{l}$ of amplified DNA for each strain or isolate was used in the agarose gels for the RAPD experiments. Random amplified polymorphic DNA experiments were replicated three times to ensure reproducibility of the assay. The PCR mixture contained $60 \mathrm{mM}$ Tris- $\mathrm{HCl}, \mathrm{pH} 8.5$, $15 \mathrm{mM}\left(\mathrm{NH}_{4}\right)_{2} \mathrm{SO}_{4}, 2 \mathrm{mM} \mathrm{MgCl}, 0.125 \mathrm{mM}$ each of dATP, dCTP, dGTP, and dTTP, 7.5 picomoles of a single 10mer, $4 \mu \mathrm{l}$ of cell suspension, and 0.625 units of Taq polymerase (Applied Biosystems, Foster City, CA). Controls containing no $H$. parasuis cells were also included.

Amplification of DNA was performed on a GeneAmp PCR System 9600 (Perkin Elmer, Boston, MA). Cells were lysed in a "hot start" step [62] at $94^{\circ} \mathrm{C}$ for $10 \mathrm{~min}$, and then amplified for 45 cycles of 1 min at $94^{\circ} \mathrm{C}$, $1.5 \mathrm{~min}$ at $36^{\circ} \mathrm{C}$, and $2 \mathrm{~min}$ at $72^{\circ} \mathrm{C}$, followed by an extension step for $10 \mathrm{~min}$ at $72^{\circ} \mathrm{C}$, then a hold step at $4^{\circ} \mathrm{C}$. PCR products were stored at $-20^{\circ} \mathrm{C}$, until they were analyzed on $1 \%$ agarose horizontal gels in TrisBorate-EDTA (TBE), pH 8.3 buffer [63] and detected by ultraviolet light illumination after staining with ethidium bromide. The DNA standard was a $1 \mathrm{~kb}$ ladder (Invitrogen, Carlsbad, CA).

\section{SDS-PAGE analysis}

For WCP lysates, bacterial cells grown in Frey's broth for $22 \mathrm{~h}$ were pelleted by centrifugation at $675 \times \mathrm{g}$ for $10 \mathrm{~min}$. Cells were washed in $0.1 \mathrm{M}$ phosphate buffered saline (PBS), pH 7.2, containing $1 \mathrm{mM}$ Pefabloc (Roche
Diagnostics, Indianapolis, IN), then resuspended at a ratio of $32 \mathrm{mg}$ cells per $100 \mu \mathrm{l}$ PBS/Pefabloc. Cells were sonicated with a microprobe (Heat Systems-Ultrasonics, Farmingdale, NY) at 50\% power for 60 1-second bursts to lyse them and centrifuged at $16,000 \times \mathrm{g}$ for $20 \mathrm{~min}$ to remove cell debris. Protein concentrations were determined by the Folin-Lowry method [64] with bovine serum albumin as a standard.

Protein $(10 \mu \mathrm{g} /$ well $)$ was applied to 10 -well NuPAGE precast $4-12 \%$ gradient Bis-Tris gels (Invitrogen). NuPAGE antioxidant (Invitrogen) was used in 3-(Nmorpholino)-propane sulfonic acid (MOPS) running buffer (Invitrogen). The protein prestained standard was BenchMark, 10-200 kDa (Invitrogen). Running conditions were $10 \mathrm{~mA} /$ gel for $15 \mathrm{~min}$, then $200 \mathrm{~V}$ for $40 \mathrm{~min}$. Gels were stained in 0.1\% Coomassie Brilliant Blue R250 in $50 \%$ methanol/10\% acetic acid and destained in $50 \%$ methanol/10\% acetic acid.

\section{Electrophoresis pattern analysis}

Gels were photographed, scanned (Kodak Image Station, Rochester, NY) and the image was digitized (Kodak Molecular Imaging Software, New Haven, CT). RAPD and protein profiles were analyzed using Gel Compar II software (Applied Maths, Austin, TX). Bands were coded as binary data (absent $=0$ or present $=1$ ), regardless of band intensity. Optimal settings for band optimization and band position tolerance levels were calculated for each primer. Primer 2 values were $2.16 \%$ for band optimization and $4.72 \%$ for band position tolerance. Similarly, primer 7 values were $1.23 \%$ and $1.06 \%$, while primer 12 values were $0.34 \%$ and $0.72 \%$, respectively. The optimal position tolerance value gives the highest group contrast: selected scores are as high as possible within groups and as low as possible between groups. Since a band matching algorithm (Dice) was used, both tolerance and optimization were calculated. Similarity matrices were obtained from single RAPD experiments and SDS-PAGE data using the Dice similarity coefficient: $F=2 n_{x y} /\left(n_{x}+n_{y}\right)$, where $n_{x}$ is the total number of fragments from isolate $X, n_{y}$ is the total number of fragments from isolate $Y$, and $n_{x y}$ is the number of fragments shared by the two isolates [65]. Additionally, a combined RAPD dendrogram analysis of all three RAPD fingerprints was derived from a composite data set of the individual experiments. Neighbor joining (NJ) dendrograms were constructed with 1000 bootstrap values. Arbitrary subdivision, clades and subclades, were derived for RAPD and WCP lysate SDS-PAGE dendrograms by examining the clades as a function of percent similarity.

\section{Statistical analysis}

Dendrograms of each single primer, composite RAPD, WCP lysate, and composite RAPD-WCP lysate were 
analyzed by the method of Hunter and Gaston which determines Simpson's index of diversity D [66]. This method determines the probability that two unrelated strains from a population will be placed into different typing groups. A D-value greater than or equal to 0.9 has been determined to be necessary for confidence in typing results [66].

\section{Abbreviations}

ATCC: American Type Culture Collection; bp: base pairs; $\beta$-NAD: $\beta$ nicotinamide adenine dinucleotide; EDTA: Ethylenediaminetetraacetic acid; ERIC-PCR: enterobacterial repetitive intergenic concensus-polymerase chain reaction; kDa: kilodalton; MEE: multilocus enzyme electrophoresis; MOPS: 3(N-morpholino)-propane sulfonic acid; MSLT: multilocus sequence typing; NT: nontypeable; OMP: outer membrane protein; PCR: polymerase chain reaction; PCR-RFLP: polymerase chain reaction-restriction fragment length polymorphism; RAPD: random amplified polymorphic DNA; SDSPAGE: sodium dodecyl sulfate polyacrylamide gel electrophoresis; WCP: whole cell protein.

\section{Competing interests}

The authors declare they have no competing interests.

\section{Authors' contributions}

ESZ did the RAPD and WCP lysate experiments and analyzed the bands using Gel Compar II, DVL suggested the use of outgroups and provided expertise in analyzing the results, and LBT was involved in drafting the manuscript and revising it critically and served as PhD mentor for ESZ. All authors read and approved the final manuscript.

\section{Acknowledgements}

We acknowledge Tim Klinefelter, lowa State University Diagnostic Laboratory, for his technical support. James Fosse and Michael Marti are also acknowledged for their support. We acknowledge Harold Ridpath for statistical expertise.

\section{Author details}

'Ruminant Diseases and Immunology, National Animal Disease Center, Agricultural Research Service, U. S. Department of Agriculture, Ames IA 50010, USA. ${ }^{2}$ Department of Ecology, Evolution and Organismal Biology, lowa State University, Ames IA 50010, USA.

Received: 20 January 2012 Accepted: 31 May 2012

Published: 15 June 2012

\section{References}

1. Nedbalcova K, Satran P, Jaglic Z, Ondriasova R, Kucerova Z: Haemophilus parasuis and Glässer's disease in pigs: a review. Veterinarni Medicina 2006, 51(5):168-179.

2. Rapp-Gabielson VJ, Kocur GJ, Clark JT, Muir SK: Haemophilus parasuis: immunity in swine after vaccination. Vet Med 1997, 92(1):83-90.

3. Maclnnes Jl, Desrosiers R: Agents of the "suis-ide diseases" of swine: Actinobacillus suis, Haemophilus parasuis, and Streptococcus suis. Can J Vet Res 1999, 63(2):83-89.

4. USDA: Swine 2006; Part II; Reference of Swine Health and Health Management Practices in the United States: In. Fort Collins, CO: United States Department of Agriculture, Animal and Plant Health Inspection Service, Veterinary Services, Centers for Epidemiology and Animal Health, National Animal Health Monitoring System 2006, 2007:1-79.

5. Kielstein P, Rapp-Gabrielson VJ: Designation of 15 serovars of Haemophilus parasuis on the basis of immunodiffusion using heat-stable antigen extracts. J Clin Microbiol 1992, 30(4):862-865.

6. Rafiee M, Blackall PJ: Establishment, validation and use of the KielsteinRapp-Gabrielson serotyping scheme for Haemophilus parasuis. Aust Vet J 2000, 78(3):172-174.

7. Tadjine M, Mittal KR, Bourdon S, Gottschalk M: Development of a new serological test for serotyping Haemophilus parasuis isolates and determination of their prevalence in North America. J Clin Microbiol 2004, 42(2):839-840.
8. Turni C, Blackall PJ: Comparison of the indirect haemagglutination and gel diffusion test for serotyping Haemophilus parasuis. Vet Microbiol 2005, 106(1-2):145-151.

9. del Río ML, Gutiérrez CB: Rodríguez Ferri EF: Value of indirect hemagglutination and coagglutination tests for serotyping Haemophilus parasuis. J Clin Microbiol 2003, 41(2):880-882.

10. Gutiérrez Martín CB Rodríguez Ferri EF De la Puente Redondo VA Navas Méndez I García del Blanco N Ladrón Boronat N: Typing of Haemophilus parasuis strains by PCR-RFLP analysis of the tbpA gene. Vet Microbiol 2003, 92(3):253-262.

11. del Río ML, Martín CB, Navas J, Gutiérrez-Muñiz B, Rodríguez-Barbosa Jl: Rodríguez Ferri EF: aroA gene PCR-RFLP diversity patterns in Haemophilus parasuis and Actinobacillus species. Res Vet Sci 2006, 80(1):55-61.

12. Oliveira S, Blackall PJ, Pijoan C: Characterization of the diversity of Haemophilus parasuis field isolates by use of serotyping and genotyping. Am J Vet Res 2003, 64(4):435-442.

13. Rafiee M, Bara M, Stephens CP, Blackall PJ: Application of ERIC-PCR for the comparison of isolates of Haemophilus parasuis. Aust Vet J 2000, 78(12):846-849.

14. Smart NL, Hurnik D, Maclnnes Jl: An investigation of enzootic Glasser's disease in a specific-pathogen-free grower-finisher facility using restriction endonuclease analysis. Can Vet J 1993, 34(8):487-490.

15. Smart NL, Miniats OP, Maclnnes Jl: Analysis of Haemophilus parasuis isolates from southern Ontario swine by restriction endonuclease fingerprinting. Can J Vet Res 1988, 52(3):319-324.

16. Blackall PJ, Trott DJ, Rapp-Gabrielson V, Hampson DJ: Analysis of Haemophilus parasuis by multilocus enzyme electrophoresis. Vet Microbiol 1997, 56(1-2):125-134

17. Olvera $A$, Cerdà-Cuéllar M, Aragón V: Study of the population structure of Haemophilus parasuis by multilocus sequence typing. Microbiology 2006 152(12):3683-3690.

18. Olvera A, Calsamiglia M, Aragón V: Genotypic diversity of Haemophilus parasuis field strains. Appl Environ Microbiol 2006, 72(6):3984-3992.

19. Jabłoński A, Zębek S, Kołacz R, Pejsak Z: Usefulness of PCR/RFLP and ERIC PCR techniques for epidemiological study of Haemophilus parasuis infections in pigs. Pol J Vet Sci 2011, 14(1):111-116.

20. Dijkman R, Wellenberg GJ, van der Heijden HMJF, Peerboom R, Olvera A, Rothkamp A, Peperkamp K: van Esch EJB: Analyses of Dutch Haemophilus parasuis isolates by serotyping, genotyping by ERIC-PCR and Hsp60 sequences and the presence of virulence associated trimeric autotransporters marker. Res Vet Sci 2011, 93:589-595.

21. Macedo NR, Oliveira SR, Lage AP, Santos JL, Araújo MR, Guedes RMC ERIC-PCR genotyping of Haemophilus parasuis isolates from Brazilian pigs. The Veterinary Journal 2011, 188:362-364.

22. Hilton $A C$, Banks JG, Penn CW: Random amplification of polymorphic DNA (RAPD) of Salmonella: strain differentiation and characterization of amplified sequences. J Appl Bacteriol 1996, 81:575-584.

23. Hopkins KL, Hilton AC: Optimization of random amplification of polymorphic DNA analysis for molecular subtyping of Escherichia coli 0157. Letters in Appl Microbiol 2001, 32:126-130.

24. Ashayeri-panah M, Efekhar F, Feizabadi MM: Development of an optimized random amplified polymorphic DNA protocol for fingerprinting Klebsiella pneumoniae. Letters in Appl Microbiol 2012, 54:272-279.

25. Wang G, Whittam TS, Berg C, Berg DE: RAPD (arbitrary primer) PCR is more sensitive than multilocus enzyme electrophoresis for distinguishing related bacterial strains. Nucleic Acids Res 1993, 21 (25):5930-5933.

26. Welsh J, MCClelland M: Fingerprinting genomes using PCR with arbitrary primers. Nucleic Acids Research 1990, 18(24):7213-7218.

27. Munoz MA, Welcome FL, Schukken YH, Zadoks RN: Molecular epidemiology of two Klebsiella pneumoniae mastitis outbreaks on a dairy farm in New York state. J Clin Microbiol 2007, 45(12):3964-3971.

28. Williams JGK, Kubelik AR, Livak KJ, Rafalski JA, Tingey SV: DNA polymorphisms ampified by arbitrary primers are useful genetic markers. Nucleic Acids Research 1990, 18(22):6531-6535.

29. Nicolet J, Paroz P, Krawinkler M: Polyacrylamide gel electrophoresis of whole-cell proteins of porcine strains of Haemophilus. Intl J Syst Bacteriol 1980, 30:69-76.

30. Oliveira S, Pijoan C: Computer-based analysis of Haemophilus parasuis protein fingerprints. Can J Vet Res 2004, 68(1):71-75. 
31. Nicolet J, Krawinkler M: Polyacrylamide gel electrophoresis, a possible taxonomical tool for Haemophilus. In: Haemophilus, Pasteurella, and Actinobacillus. Edited by Kilian M, Fredricksen W, Biberstein EL. San Francisco: Academic Press 1981:205-212

32. Rapp-Gabrielson VJ, Oliveira SR, Pijoan C: Haemophilus parasuis. In: Diseases of Swine. Blackwell Publishing: Edited by Straw BE, Zimmerman JJ, D'Allaire S, Taylor DJ, 9th edition, Ames, IA; 2006:681-690.

33. Ruiz A, Oliveira S, Torremorell M, Pijoan C: Outer membrane proteins and DNA profiles in strains of Haemophilus parasuis recovered from systemic and respiratory sites. J Clin Microbiol 2001, 39(5):1757-1762.

34. Peerbooms PGH, Engelen MN, Stokman DA, van Benthem BH, van Weert ML, Bruisten SM, van Belkum A, Coutinho RA: Nasopharyngeal carriage of potential bacterial pathogens related to day care attendance, with special reference to the molecular epidemiology of Haemophilus influenzae. J Clin Microbiol 2002, 40(8):2832-2836.

35. Deplano A, De Mendonça R, De Ryck R, Struelens MJ: External quality assessment of molecular typing of Staphylococcus aureus isolates by a network of laboratories. J Clin Microbiol 2006, 44(9):3236-3244.

36. Di Cagno R, De Angelis M, Gallo G, Settanni L, Berloco MG, Siragusa S, Parente E, Corsetti A, Gobbetti M: Genotypic and phenotypic diversity of Lactobacillus rossiae strains isolated from sourdough. J Appl Microbiol 2007, 103(4):821-835.

37. Rapp-Gabrielson VJ, Gabrielson DA, Musser JM: Phenotypic and genotypic diversity of Haemophilus parasuis. In. The Royal Netherlands Veterinary Association: Proc 12th Int Pig Vet Soc Congr: 1992; The Hague; 334.

38. Stadejek $T$, Björklund $H$, Bascuñana CR, Ciabatti IM, Scicluna MT, Amaddeo D, McCollum WH, Autorino GL, Timoney PJ, Paton DJ, Klingeborn, B, Belák, S: Genetic diversity of equine arteritis virus. J Gen Virol 1999, 80:691-699.

39. Alland D, Whittam TS, Murray MB, Cave MD, Hazbon M, Dix K, Kokoris M, Duesterhoeft A, Eisen JA, Fraser CM, Fleischmann, RD: Modeling bacterial evolution with comparative-genome-based marker systems: application to Mycobacterium tuberculosis evolution and pathogenesis. J Bacteriol 2003, 185(11):3392-3399.

40. Koonin EV, Makarova KS, Aravind L: Horizontal gene transfer in prokaryotes: quantification and classificaton. Annu Rev Microbiol 2001, 55:709-742.

41. Zehr ES, Tabatabai LB: Detection of a bacteriophage gene encoding a Mu-like portal protein in Haemophilus parasuis reference strains and field isolates by nested polymerase chain reaction. JVet Diagn Invest 2011, 23(3):538-542

42. Yue $M$, Yang F, Yang J, Bei W, Cai X, Chen L, Dong J, Zhou R, Jin M, Jin Q, Chen, $\mathrm{H}$ : Complete genome sequence of Haemophilus parasuis $\mathrm{SH} 0165$. $J$ Bacteriol 2009, 191(4):1359-1360.

43. Melnikow E, Dornan S, Sargent C, Duszenko M, Evans G, Gunkel N, Selzer PM, Ullrich HJ: Microarray analysis of Haemophilus parasuis gene expression under in vitro growth conditions mimicking the in vivo environment. Vet Microbiol 2005, 110(3-4):255-263.

44. Morgan GJ, Hatfull GF, Casjens S, Hendrix RW: Bacteriophage Mu genome sequence: analysis and comparison with Mu-like prophages in Haemophilus, Neisseria and Deinococcus. J Mol Biol 2002, 317(3):337-359.

45. Campoy S, Aranda J, Àlvarez G, Barbé J, Llagostera M: Isolation and sequencing of a temperate transducing phage for Pasteurella multocida. Appl Environ Microbiol 2006, 72(5):3154-3160.

46. Gioia J, Qin X, Jiang H, Clinkenbeard K, Lo R, Liu Y, Fox GE, Yerrapragada S, McLeod MP, McNeill TZ, Hemphill, L, Sodergren, E, Wang, Q, Muzny, DM Homsi, FJ, Weinstock, GM, Highlander, SK The genome sequence of Mannheimia haemolytica A1: insights into virulence, natural competence, and Pasteurellaceae phylogeny. J Bacteriol 2006, 188(20):7257-7266.

47. Davies RL, Lee I: Diversity of temperate bacteriophages induced in bovine and ovine Mannheimia haemolytica isolates and identification of a new P2-like phage. FEMS Microbiol Lett 2006, 260:162-170.

48. Guo L, Zhang J, Xu C, Zhao Y, Ren T, Zhang B, Fan H, Liao M: Molecular characterization of fluoroquinolone resistance in Haemophilus parasuis isolated from pigs in South China. J Antimicrob Chemther 2011 66:539-542.

49. Kang M, Zhou R, Liu L, Langford PR, Chen $\mathrm{H}$ : Analysis of an Actinobacillus pleuropneumoniae multi-resistance plasmid, pHB0503. Plasmid 2009, 61:135-139.

50. Bigas A, Garrido ME, de Rozas AM, Badiola I, Barbé J, Llagostera M: Development of a genetic manipulation system for Haemophilus parasuis. Vet Microbiol 2005, 105(3-4):223-228.
51. Rapp-Gabielson VJ, Gabrielson DA: Prevalance of Haemophilus parasuis serovars among isolates from swine. Am J Vet Res 1992, 53:659-664.

52. Zulkifli Y, Alitheen NB, Son R, Raha AR, Samuel L, Yeap SK, Nishibuchi M: Random amplified polymorphic DNA-PCR and ERIC-PCR analysis on Vibrio parahaemolyticus isolated from cockles in Padang, Indonesia. Intl Food Res J 2009, 16:141-150.

53. Cai X, Chen H, Blackall PJ, Yin Z, Wang L, Liu Z, Jin M: Serological characterization of Haemophilus parasuis isolates from China. Vet Microbiol 2005, 20(111):231-236.

54. Angen $\varnothing$, Svensmark B, Mittal KR: Serological characterization of Danish Haemophilus parasuis isolates. Vet Microbiol 2004, 103(3-4):255-258.

55. Rapp-Gabrielson VJ, Kocur GJ, Clark JT, Muir SK: Haemophilus parasuis: immunity in swine after vaccination. Vet Med 1997, 92(1):83-90.

56. Morozumi T, Nicolet J: Morphological variations of Haemophilus parasuis strains. J Clin Microbiol 1986, 23(1):138-142.

57. Rapp-Gabrielson VJ, Gabrielson DA: Prevalence of Haemophilus parasuis serovars among isolates from swine. Am J Vet Res 1992, 53(5):659-664.

58. Rosner H, Kielstein P, Müller W, Rohrmann B: Relationship between serotype, virulence, and SDS-PAGE protein patterns of Haemophilus parasuis. Dtsch Tierärzl Wschr 1991, 98(9):327-330.

59. Blackall PJ, Rapp-Gabrielson VJ, Hampson DJ: Serological characterisation of Haemophilus parasuis isolates from Australian pigs. Aust Vet J 1996, 73(3):93-95.

60. Hahn MW: Bias in phylogenetic tree reconciliation methods: implications for vertebrate genome evolution. Genome Biology 2007, 8(7):R141.141-R141.149.

61. Maddison WP, Donoghue MJ, Maddison DR: Outgroup analysis and parsimony. Syst Zool 1984, 33:83-103.

62. Joshi AK, Baichwal V, Ames GF: Rapid polymerase chain reaction amplification using intact bacterial cells. Biotechniques 1991, 10(1):44-45.

63. Maniatis T, Fritsch EF, Sambrook J: Molecular cloning: a laboratory manual:: Cold Spring Harbor Laboratory, NY; 1982:545 pp..

64. Lowry OH, Rosenbrough NJ, Farr AL, Randall RJ: Protein measurement with the Folin phenol reagent. J Biol Chem 1951, 193(1):265-275.

65. Houang ET, Chu Y, Ng T, Cheng AF: Study of the relatedness of isolates of Shigella flexneri and Shigella sonnei obtained in 1986 and 1987 and in 1994 and 1995 from Hong Kong. J Clin Microbiol 1998, 36(9):2404-2407.

66. Hunter PR, Gaston M: Numerical index of the discriminatory ability of typing systems: an application of Simpson's index of diversity. J Clin Microbiol 1988, 26:2465-2466.

doi:10.1186/1471-2180-12-108

Cite this article as: Zehr et al:: Comparison of Haemophilus parasuis reference strains and field isolates by using random amplified polymorphic DNA and protein profiles. BMC Microbiology 2012 12:108

\section{Submit your next manuscript to BioMed Central and take full advantage of:}

- Convenient online submission

- Thorough peer review

- No space constraints or color figure charges

- Immediate publication on acceptance

- Inclusion in PubMed, CAS, Scopus and Google Scholar

- Research which is freely available for redistribution
C) Biomed Central 